\title{
Fabricators, Industry and Academia: The Technology Transfer Challenge.
}

\section{Ian Gibson}

Departmeht of Mechanical Engineering

The Inniversity of Hong Kong

\begin{abstract}
Automated Fabrication is a cornerstone of the current revolution in minufacturing technology. The everincreasing number of machines and the widening variety of applications both state that the technology is here to stay. But, there are still many lessons to be learnt before we are faced with a mature, stable and fully integrated technology.
\end{abstract}

Currently, industry uses automated fabricators to gain a market advantage. Eventually they will be used in order to avoid being left behind. The role of academia is to guide industry through these developmental stages and to eusure the transition to maturity is snooth.

It is important to analyse the roles of industry and academia in supporting this new technology. There are a number of strategies for gaining ind ustrial acceptance and the experience of the University of Hong Kong and other institutions in Hong Kong, in liaison with local industry may help future technology transfer programmes.

\section{INTRODUCTION}

Technology transfer is the process of converting ideas into commercial products. The premise is that ideas are housed in one place (R\&D departments, research institutes, inventors garages, etc.) alld they have to be transferred into the wider market with the help of industry. When R\&D people have an idea for new technology, often one of the initial stages of developr ent is the building of a prototype. This prototype, if successtiul, will prove the idea and provide a means for development and embodiment. Eventually the prototype will demonstrate its value to a wider market and require commercial exploitation. Such exploitation is generally undertaken by industry.

The problem is how do these ideas become recognised for what they are worth? Industry, in general, is reluctant to large risks and would prefer to know that it can sell a product before any commitment to manufacture. Similarly, if a new product is designed to provide a competitive edge, companies would like to know how significant that advantage is going to be before committing resources. Whilst realising that advahces must be made in order to stay ahead, industry would prefer to keep existing equipment until it knows that an advantage can be gained.

Technology transfer is required in at least 2 forms:-

1. For new technology that has never been tried before. This technology can pay the largest dividends to those prepared to take the risk in the early stages, gaining a competitive advantage (and charging a premium) before the technology becomes commonplace. An example here is the Sony Walkman.

2. For existing technology, but with new application areas. Often it is unclear whether further development is necessary and industry may not be prepared to take the risk or know when it is appropriate to invest in the technology. Examples in this case are the Personal Computer and the technology associated with the Internet.

Automated Fabrication technology, originally in the first form, now requires technology transfer of the second form. The technology was commercialised in the mid-80s and some companies have made extensive use of it to great benefit. However, many feel that this technology may become widespread with many millions of machines sold (total sales to date are in the order of a few thousand). It is the job of technology transfer organisations (TTOs) to ease the transition and ensure that the technology does not die an untimely death before it has chance to demonstrate its true potential.

This paper deals with the particular situation of Automated Fabrication and the problems surrounding transfer of this technology to industry. It also deals with the situation where academia is involved in the transfer process. A range of techniques used for transfer of automated fabrication equipment will be discussed with particular reference to the experiences of The University of Hong Kong (and other institutions in Hong Kong) and Hong Kong industry. Whilst specific, it is thought that at least some of the concepts discussed can be generalised to a much wider range of technologies, geographical areas and industries.

\section{AUTOMATED FABRICATION}

Automated Fabrication (also referred to as Rapid Ptototyping, Free-Form Fabrication, etc.) is a term that represents a range of manufacturing technologies. The principle is that a design can be fed into an automated 
fabrication machine and a complete physical part results. The starting point of this process is a computer based representation of the part; a 3D solid $\mathrm{CAD}$ model. This model contains all the geometrical data necessary to make the part. The automated fabrication machine (or fabricator) takes this data and redefines it in the form of horizontal slices. Each slice is recreated in the machine as a thin layer of physically solid material. Slices are then re-combined within the machine to form a complete part. The quality of this physical representation of the original $\mathrm{CAD}$ data is somewhat dependent on the slice thickness, which is commonly in the order of $0.1 \mathrm{~mm}$ or better. There are a number of different types of fabricator, using different technologies, with a variety of materials. All machines however use the layer-based approach.

The layer-based approach means that the complex, 3D problem is diluted into a sequence of simpler, 2-dimensional tasks. This means that the process is generally independent of the complexity of form and rather more dependent on the size and, in particular, the height of the component. Comparable machining processes are much more dependent on form and therefore the advantage of automated fabrication is in the processing of complex geometry in a single, automated stage in a predictable (and generally much quicker) time. For one-off manufacture, which is often required in the early stages of product development, this process is at its most valuable. Products can be designed, assessed and modified in a matter of days (or even hours) rather than weeks using conventional technology.

If that were the entire story then automated fabrication machines would be termed as requiring category one technology transfer and permitted to take their course as a good or bad idea, exploited in perhaps the same way as laser printers. However, as these machines have increased in popularity, so the number of applications has also increased. Originally fabricators were used to create 'visualisation' parts that for the initial stages of design to allow the designer to communicate the general form to others. Materials, and the accuracy of the original machines, were too poor to perform many other tasks. However, new materials and better control and understanding of the processes made it possible to extend the uses to functional prototypes which could also be used to test the parts and give designers a much better picture of what the final product would be like. Now, it is possible in many cases to create parts in the final designated material, albeit in relatively small numbers and/or with less accuracy than some other machining processes. These 'rapid tooling' processes represent the cutting edge of this technology and it is this area that both excites and concerns manufacturers. The advantages may be enormous but so is the risk if the technology does not meet requirements or live up to expectations. It is up to the TTOs therefore to present this technology in a manner that shows whether, and when, it is worthwhile investing in.

\section{THE ROLE OF THE TECHNOLOGY TRANSFER}

\section{ORGANISATION}

The TTO is the champion of high technology. It has to be convinced that there is some worth in the technology that it is trying to promote. However, such an organisation is not a salesroom for the technology and it must be objective. No technology is a panacea and there must be an understanding that there are limitations in what is on offer and lessons to be learnt. There must be an awareness that much of what is available has not been fully tested against all the requirements of many industrial or consumer applications. Automated fabrication is a prime example. There are a number of manufacturers of this technology and it can be difficult to match industrial requirements with particular machines and processes, generally because the advantages often depend on how the users integrate these machines with their existing operations.

There are a number of functions that a TTO must perform, these include:-

Recognition of the needs of industry: Representatives from the TTO must have close links with industry. It is not sufficient just to have people who have worked with industry, but it must have people from industry regularly visiting and explaining their needs within the current economic climate. Therefore, the more companies that the organisation has links with and the wider the range of interests, the more promising the future for that technology.

Nurturing the transfer of the technology: Investing in the technology is an important requirement for the TTO. The technology must be well presented, up-to-date, with good support and backed up with an abundant, in-depth knowledge of all its functions. Whilst not being able to understand every need of industry, it should be possible to answer any questions relating to the technology itself, thus being able to isolate a new application or a problem local to a particular branch of industry.

Provide a basis for applied and basic research: Technology transfer is not just about stating the current position, it is also about looking into the future. To maintain credibility, it is important that the organisations concerned strive to develop the technology it is promoting. Being a focus for a range of industries investigating new areas puts the organisation in an ideal position to extend technological development.

From the above it can be seen that, whilst it is possible for companies (e.g. machine vendors) to perform all three functions, it may be difficult in terms of bias and available resources to get the message across properly to industrial 
users. Government sponsored organisations and educational institutions are probably in the best position to perform technology transfer.

\section{STRATEGIES FOR TECHNOLOGY TRANSFER}

With respect to autonated fabrication, the technology transfer process appears to be realised in three ways; popularisation, training, and application (see table 1). Popularisation in general relates to publicity and involves making people aware of the technology. With automated fabrication this means communicating with manufacturers, modelmakers and toolmakers. This is a relatively simple process since there are many good trade shows and fabricators are relatively easy to display with many of the machines being transportable and capable of making eyecatching components. Another effective process is the use of seminars, although attracting less people, there is a tendency to get the message across to the right ones and it is not a difficult process to describe. Publicity outside of the technically aware is more difficult since most consumers tend to accept the products they are faced with, without understanding any of the problems concerning their manufacture. Automated fabrication machines do have the ability to make seemingly impossible structures (e.g. concentric balls, interlocking chains without parting lines, etc.) which makes it possible to illustrate some of the advantages of the technology.

\begin{tabular}{|c|c|}
\hline Hunctoo & Attytles \\
\hline Popularisation & $\begin{array}{l}\text { Exhibitions, seminars, press releases, example } \\
\text { parts, representations on professional societies, } \\
\text { etc. }\end{array}$ \\
\hline Training & $\begin{array}{l}\text { Workshops, case-studies (typical examples), } \\
\text { consultancy, specialist publications, vendor } \\
\text { liaison }\end{array}$ \\
\hline Applications & $\begin{array}{l}\text { Benchmarks, case-studies, specialist } \\
\text { publications, consultancy (productivity analysis), } \\
\text { company liaison }\end{array}$ \\
\hline
\end{tabular}

\section{TABLE I STRATEGIEN FOR TECHNOLOGY TRANSFER}

All TTOs should be heavily involved with training. Training is the only effective way of ensuring that the technology develops and integrates with conventional technology. When a skilled machine worker understands the advantages fabricators can provide compared with other machines, only then will it be fully accepted. Training can come in many forms but must be relatively intensive with the opportunity to see at first hand or (better still) hands-on. It helps to have some background understanding of the process from reading books/articles on the subject, but full appreciation must be by comparison with exisling machines. The skills required are more software than hardware with even the required hardware knowledge being different from conventional machine technology (e.g. basic chemistry, clean-room environment, computer networking, etc.).

Another way of obtaining industry acceptance is to create parts in the form of benchmarks or case-studies. Whereas training relates to operator use, applications appeal to managers and executives. It is important to create the correct impression by ensuring that in-house skills are of the highest quality and to ensure parts are made in the best possible way. Much of this involves direct liaison with industry so that the needs of industry are correctly assessed and catered for. It is also important to be as open as possible and to admit defeat where a job cannot be done.

\section{THE HONG KONG EXPERIENCE}

Compared with the US and much of Europe, automated fabrication in Hong Kong is very much in the early stages. Unlike some other countries, the implementation has been relatively slow and institutionally driven rather than from industry. There have been machines in Hong Kong for over 4 years but only recently has there been any marked industrial interest. By end 1997 it is expected that the number of machines will increase from 7 (in late 1996) to around 25 machines in Hong Kong with around $25 \%$ in industrial use. In future years one can expect this ratio to increase dramatically. Even today, many of the machines in Hong Kong are used for commercial or semi-commercial purposes.

The first stages of technology transfer are showing signs of success in terms of obtaining a foothold in local industry. The focus of the TTOs has now shifted to the more value added processes, in particular rapid tooling. Currently, many tooling applications are well beyond the scope of most fabricators. Hong Kong has a number of industries that have only recently become aware of this technology for tooling purposes as well as having different attitudes towards economic development when compared with the US and Europe. The proximity of China, supplying most of the labour for Hong Kong based manufacturers, also has an effect on the cost and quality of products made in the region. It is therefore important to note that what is appropriate to other countries may not be suitable for Hong Kong and case studies in particular must focus on local industry.

There have been a number of technology transfer initiatives that have been either directly or indirectly sponsored by Hong Kong government:-

The Hong Kong Productivity Council is a semicommercial, government sponsored organisation charged with a specific role of technology transfer. In 1994, it was the first Hong Kong establishment to obtain a fabricator and in 1996, a dedicated 
centre for rapid prototyping was established with two machines (both Stereolithography machines), a laser scanner, a large variety of solid modeling $\mathrm{CAD}$ systems and a number of tooling facilities, most notably a vacuum metal casting system.

Hong Kong University obtained a grant in 1996 to develop its existing automated fabrication facility to include a rapid tooling process. Using the Selective Laser Sintering (SLS) process (installed in 1995), a furnace and $C A D$ support facilities were installed to make it possible to directly produce metal injection mould inserts. Funded by the Hong Kong Government Industry Department, this project was specifically set up to perform industrial casestudies.

Hong Kong Polytechnic University and the Technical Colleges in Hong Kong have recently made substantial investments in automated fabrication technology. By end 1997, there will be around 10 machines in use with hundreds of students having access to them through direct training programs and many more using them for design projects, metrology experiments and as the basis for toolmaking exercises. This technology is also available for use to industry.

All applications for funding these projects have been made individually and do not represent any focused initiative from the Hong Kong government, although there is a wider underlying trend for the Hong Kong Government Industry Department to support technological development. Recently, TTOs and industry supporters formed the Hong Kong Society for Rapid Prototyping and Tooling. Backed by other industry groups (Productivity Council, Plastics Technology Centre, Mould and Die Council, Society of Manufacturing Engineers), this society aims at a formal representation of this technology to Hong Kong in general.

It is possible that some form of regulation of automated fabrication. business may have to take place in the near future. Recently, a small number of independent service bureaus have started offering this technology in Hong Kong. Many potential users of the technology are too small to invest in the processes directly (or indeed have insufficient work to justify the investment). Sub-contracting to bureaus makes sense, but it is difficult for this to be profitable when there are so many machines institutionally available with few regulations concerning the work that they can do for outside companies. Subsidised by the institutions and by the machine vendors, chargeable rates are relatively low in Hong Kong when compared with other parts of the world. Hong Kong academia has some substantial part to play in how this problem is resolved.

\section{CONCLUSIONS}

This paper has discussed the subject of technology transfer from the point of view of automated fabrication technology. It has defined technology transfer and why it must be done and why it makes sense to place it in the hands of academia. Some strategies for technology transfer have been put forward and the major initiatives within Hong Kong have been described.

The development of the technology has also been described in order to gauge the level of maturity and ascertain the potential for further growth. The situation in Hong Kong is currently lagging the US and Europe. Some forecast significant development in the South China region however, with Hong Kong being a significant influence on that development.

It is not correct to say that this technology has been transferred and that academia has done its job and can now get on with research and/or devote its attentions to other technologies. Rapid tooling production is still in its infancy and does require additional focus and data collection to determine its impact and economic potential so the focus has only changed slightly.

Finally it is important to realise that, with its inherent flexibility of use, automated fabricators can be a means to ease technology transfer of other products as well as in need of continued effort in transferring this exciting technology to industry.

\section{BIBLIOGRAPHY}

The following text sources may be useful in understanding the automated fabrication process and potential benefits to industry

M.Burns, 'Automated Fabrication', pub. by PTR Prentice Hall, 1993, ISBN 0131194623.

T.Wohlers, 'State of the Industry, Rapid Prototyping 1995-6 Worldwide Report', pub. by the Society of Manufacturing Engineers, April 1996.

P.F.Jacobs, 'Rapid Prototyping and Manufacturing: Fundamentals of Stereolithography', pub. by the Society of Manufacturing Engineers, 1992, ISBN 0872634256.

P.F.Jacobs, 'Stereolithography and other RP\&M Technologies : from Rapid Prototyping to Rapid Tooling', pub. by the Society of Manufacturing Engineers, 1996, ISBN 0872634671

Rapid Prototyping Journal, pub. by MCB University Press, ISSN 1355 2546, from 1996. 